\title{
New Approaches for the Treatment of Alzheimer's Disease
}

Paul V. Fish, ${ }^{\mathrm{a}, \mathrm{b}, *}$ David Steadman, ${ }^{a}$ Elliott D. Bayle, ${ }^{\mathrm{a}, \mathrm{b}}$ and Paul Whiting ${ }^{\mathrm{a}, \mathrm{c}}$

a Alzheimer's Research UK UCL Drug Discovery Institute, The Cruciform Building, University College London, Gower Street, London WC1N 1E 6BT, UK.

${ }^{\mathrm{b}}$ The Francis Crick Institute, 1 Midland Road, Kings Cross, London NW1 1AT, UK.

c The Dementia Research Institute, The Cruciform Building, University College London, Gower Street, London WC1N 1E 6BT, UK.

Key words: $\quad$ Alzheimer's disease, neurodegeneration, neuroinflammation, drug discovery pipeline, symptomatic treatments, disease modification. 


\section{Graphical Abstract}

\section{New Approaches for the Treatment of Alzheimer's Disease}

Paul V. Fish, David Steadman, Elliott D. Bayle, Paul Whiting
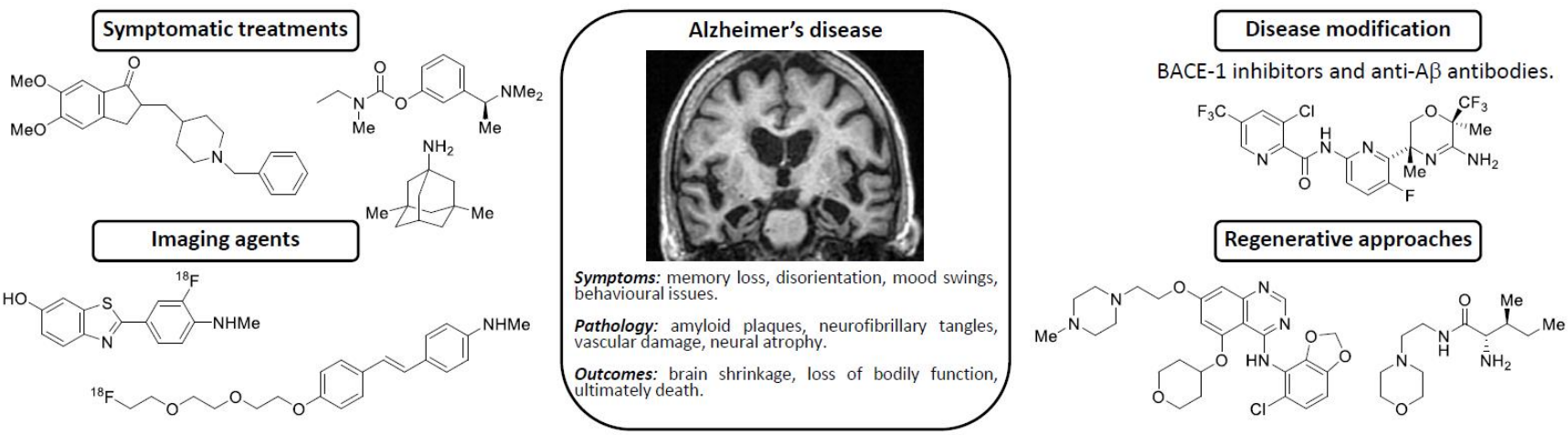


\begin{abstract}
Alzheimer's disease (AD) is the most prevalent chronic neurodegenerative disease. Current approved therapies are symptomatic treatments having some effect on cognitive function. Therapies that target $\beta$ amyloid $(A \beta)$ have been the focus of efforts to develop a disease modification treatment for AD but these approaches have failed to show any clinical benefit so far. Beyond the 'A $\beta$ hypothesis', there are a number of newer approaches to treat $A D$ with neuroinflammation emerging as a very active area of research based on risk gene analysis. This short review will summarize approved drug therapies, recent clinical trials and new approaches for the treatment of AD.
\end{abstract}




\section{Introduction}

Alzheimer's disease (AD) is the most prevalent chronic neurodegenerative disease with 5.7 million people living with the disease in the USA alone and this is projected to increase to 13.8 million people by $2050 .{ }^{1}$ Globally, the number of people currently suffering with dementia is estimated to be 50 million of which 30-35 million have AD. ${ }^{2}$ The risk of developing the disease is influenced by both genetic and environmental factors, however the biggest risk factor by far is age; the older you are the more likely you are to develop the disease but it is not an inevitable part of ageing. For instance, about one in 50 people aged between 65 to 69 have dementia, and this figure rises to one in five for those aged between 85 to 89. ${ }^{2}$ Given the global increase in life expectancy, this represents a huge societal and economic challenge with the impact extending to those living with $A D$, along with their caregivers and family. The disease often manifests itself initially as short term memory loss and as the disease progresses symptoms include language problems, disorientation, mood swings and behavioural issues (agitation, sleep changes, psychosis). Eventually the disease progresses to loss of bodily function and ultimately to death.
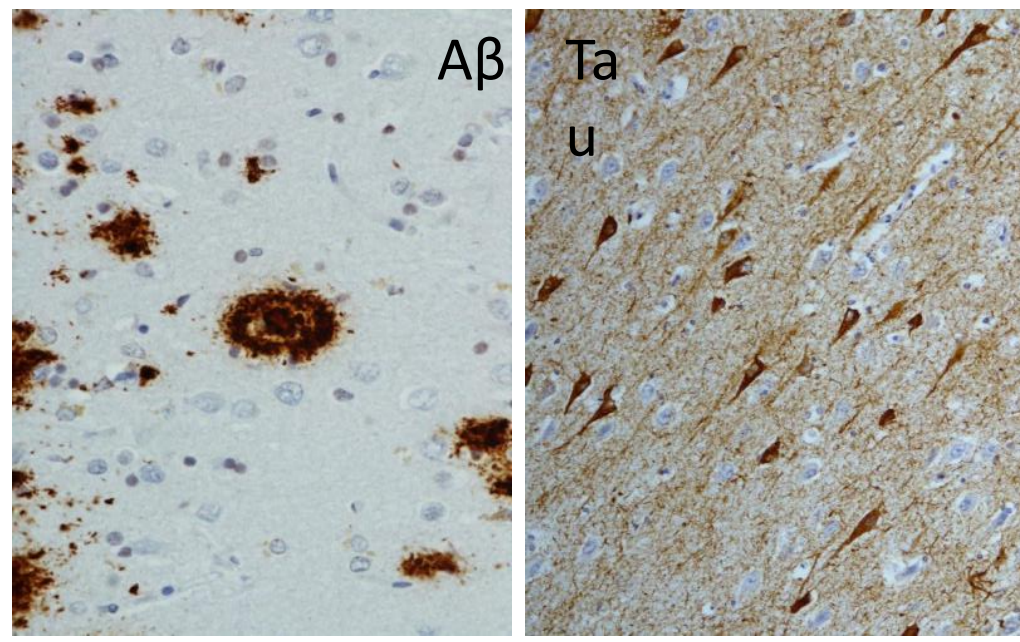

Figure 1: Postmortem tissue samples from Alzheimer's disease (AD) patient brains reveal $A D$ pathology including amyloid- $\beta(A \beta)$ plaques and Tau tangles. Photographic image courtesy of Dr. Tammaryn Lashley at the Queen Square Brain Bank for Neurological Disorders (UCL Queen Square Institute of Neurology). Copyright Tammaryn Lashley 2018.

There are two pathological hallmarks of the disease found in the brain of individuals with AD: extracellular amyloid plaques and intracellular neurofibrillary tangles (Figure 1). ${ }^{3}$ These were first recognised in 1906 by Alois Alzheimer after whom the disease is named. ${ }^{3 b}$ We now recognise that the plaques are largely composed of $\beta$-amyloid peptides (A $\beta$ ) derived from amyloid precursor protein (APP), while the neurofibrillary tangles are composed of the tau protein (microtubule associated protein). As the disease advances, these pathologies progress along with brain shrinkage due to neuronal atrophy. (Figure 2). 

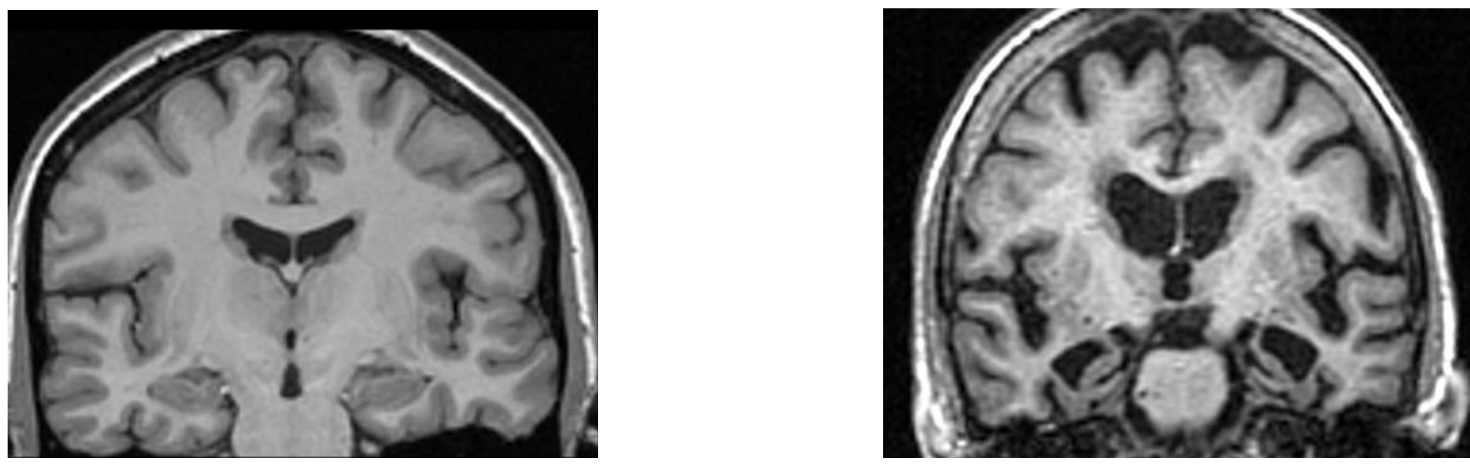

Figure 2: Comparison of MRI scans of healthy volunteer (left, control) and Alzheimer's disease patient (right). The AD brain shows significant atrophy, dilation of the lateral ventricle and a smaller hippocampus. Images courtesy of Nick Fox (UCL Queen Square Institute of Neurology). Copyright Nick Fox.

Human genetics has significantly enabled our understanding of the disease and the approaches that have been taken to discover new therapies. Rare autosomal dominant mutations in three genes, APP, presenilin 1 (PSEN1) and presenilin 2 (PSEN2) cause familial Alzheimer's disease (FAD). FAD accounts for $2-3 \%$ of $A D$ cases and usually has an earlier onset with symptoms developing in people in their $30 \mathrm{~s}$ or $40 \mathrm{~s}$. In 1992, Hardy and Higgins postulated that the "deposition of amyloid $\beta$ protein (A $\beta P$ ) ... is the causative agent of Alzheimer's pathology and that neurofibrillary tangles, cell loss, vascular damage, and dementia follow as a direct result of this deposition". ${ }^{4}$ Given that the APP protein is the source of A $\beta$ found in plaques, and that it subsequently became clear that the PSEN genes encode the catalytic subunit of the $\gamma-$ secretase enzyme that cleaves APP (along with $\beta$-secretase) leading to the generation of A $\beta$ peptides, this led to the molecular basis of the " $\beta$-amyloid hypothesis of $A D$ ". How $A \beta$ peptides (be that soluble, oligomeric, or plaque) leads to cell death remains controversial. Similarly, how tau tangles affect neural function, the relationship between $\beta$-amyloid and tau tangles, and the apparent inter-neuronal spread of tau, are all areas of intense research.

The recent clinical failures (discussed below) of a number of therapeutics that attempt to test the " $\beta$ amyloid hypothesis of $A D^{\prime \prime}$ might lead to the suggestion that this hypothesis has been disproven. However, it is our view that the $A \beta$ hypothesis is still central to causation of the disease and has yet to be adequately tested either because of flaws in the various therapeutics tested or because the clinical trials need to be performed on subjects much earlier in the disease process. Whether $A \beta$ or tau are the better drug target is unknown at this moment, and perhaps a moot point; both appear to be central to the disease process and so it is likely that combination therapies modulating both pathologies will ultimately be most successful. 
As well as the identification of autosomal dominant mutations, extensive genome wide association studies (GWAS) in AD have led to the identification of numerous risk alleles. ${ }^{5}$ The most significant of these is apolipoprotein E4 (ApoE4) with homozygosity leading to an 8 fold increase in risk of AD. However, despite a significant effort, the biology that underpins this increased risk conferred by ApoE4 remains to be fully understood. In the absence of this knowledge, it remains unclear if positive or negative modulation of ApoE4 would be beneficial. Furthermore, ApoE is a lipid-binding protein and is likely to be a challenging drug target for a small molecule even when there is an understanding as to the required modulation of function. A group of other genes identified through GWAS all point towards a role for neuroinflammation and microglial cells in AD. This is becoming an important area of research.

Therapeutic approaches to $A D$, like most chronic degenerative diseases, can be broadly divided into three categories: symptomatic, disease modifying, and regenerative. Current approved therapies (cholinesterase inhibitors and glutamate antagonists) are symptomatic having some effect on cognitive function. There remains a significant unmet medical need for symptomatic treatments that impact more effectively the cognitive domain and also the other distressing symptoms such as agitation, psychosis and sleep disturbance. ${ }^{6}$ Most ongoing efforts to find new therapies are focussing on disease modification/disease progression; the premise is that if the onset of the disease can be delayed, or the progression of the disease slowed, then people will live longer without the developing AD. To date approaches have largely focussed around intervention in the $A \beta$ cascade and tau biology. The third category, regeneration, remains very much a hypothetical approach. Regenerating a diseased brain, replacing lost neurons and circuitry, is arguably a step too far for $A D$ at this time.

Clinical trials for $A D$ have proven challenging, largely because the rate of disease progression is many months (meaning the trials often last 18 months or more), and the registerable endpoints recognised by the regulatory agencies are measures of cognitive performance. ${ }^{7}$ These are generally considered less robust an endpoint than biochemical or physiological measures. Good strides have however been made with pharmacodynamic endpoints. For instance, cerebrospinal fluid (CSF) A $\beta$ concentrations are routinely used as a biomarker for assessing compounds whose mechanism is inhibition of the enzymes that generate A $\beta$ from APP. ${ }^{8}$ Similarly, there are now good positron emission tomography (PET) ligands available that support visualisation and quantification of both $A \beta$ plaques and tau tangles. This is beginning to enable the correlation of the change in these classical pathological markers of the disease with disease progression as measured by the cognitive scales. ${ }^{9}$ For example florbetaben (1), flutemetamol (2) and florbetapir (3) are diagnostic radiotracers developed for routine clinical application to visualize $A \beta$ plaques in the brain. ${ }^{18} \mathrm{~F}$-Flutemetamol (2, Vizamyl) is indicated for PET imaging of A $\beta$ neuritic plaque 
density in the brains of adult patients with cognitive impairment who are being evaluated for AD (Figure 3).<smiles>CNc1ccc(/C=C/c2ccc(OCCOCCOCC[18F])cc2)cc1</smiles>

florbetaben F-18 (1)<smiles>CNc1ccc(-c2nc3ccc(O)cc3s2)cc1F</smiles>

flutemetamol F-18 (2)<smiles>CNc1ccc(/C=C/c2ccc(OCCOCCOCC[18F])nc2)cc1</smiles>

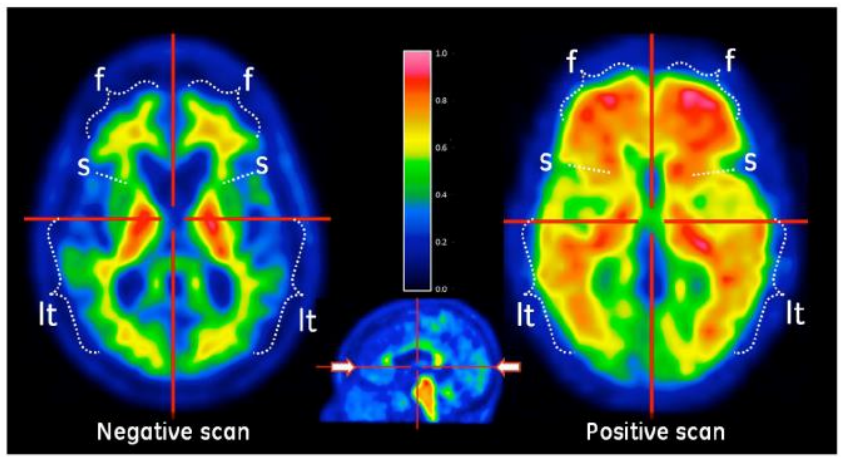

Figure 3: Axial view of negative (left) and positive (right) Vizamyl scans. Frontal (f), lateral temporal (it) and striatal (s) regions of the brain. Image taken from Vizamyl prescribing information, revised 02/2017. http://www.gevizamyl.com/us/wp-content/uploads/2017/02/43-1067C-Vizamyl1.pdf. Copyright GE Healthcare.

\section{Approved Therapies}

There are currently no approved therapies which directly target AD pathology. Existing treatments are symptomatic, aimed at ameliorating cognitive function through two different modes of action: agonism of the cholinergic system and antagonism of the $N$-methyl-D-aspartate receptor (NMDA-receptor).

Since the 1970s, the cholinergic system has been shown to have an important role in cognition, with the observation that anticholinergic drugs, such as scopolamine, have negative effects on cognitive function. ${ }^{10}$ Indeed, it has recently been shown that high levels of cumulative exposure to anticholinergics correspond to an increased risk of dementia. ${ }^{11}$ The current main treatment strategy for $A D$, as recently reviewed, ${ }^{12}$ is therefore to increase levels of acetylcholine via the administration of compounds that inhibit acetylcholinesterase, the enzyme which catalyzes its degradation. There are currently three FDAapproved cholinesterase (ChE) inhibitors: rivastigmine (4), donepezil (5), and galantamine (6). 
<smiles>CCN(C)C(=O)Oc1cccc(C(C)C)c1</smiles>

rivastigmine (4)

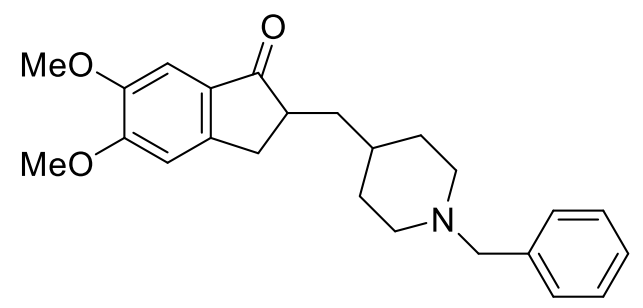

donepezil (5)<smiles>[Y6]N1CC[C@]23C=C[C@H](O)C[C@@H]2Oc2c(OC)ccc(c23)C1</smiles>

galantamine (6)

ChE inhibitors have been shown not only to have statistically significant effects on patient cognition and function, ${ }^{13,14}$ but also positive outcomes on the societal and economic burden of $A D$, as demonstrated by an observed delay in nursing home placement, ${ }^{15}$ and reduced caregiver burden. ${ }^{16}$ Since 2007, rivastigmine (4) has been available as a transdermal patch, which has also been shown to improve caregiver burden and treatment adherence. ${ }^{17}$ The long-term benefits of ChE inhibition are debatable however, with some studies claiming long-term efficacy ${ }^{18}$ and others showing no improvement in rate-of-progression to $A D$ compared to placebo after 3 years. ${ }^{19}$

While ChE inhibitors have shown clinical use for mild to moderate $A D$, there were no available treatments for patients with moderate to severe AD until 2003, when the FDA approved memantine (7). Memantine acts as a non-competitive, fast off-rate NMDA-receptor antagonist to target glutamatergic dysfunction ${ }^{20}$ and exhibits its mode-of-action by binding to the open state of the NMDA receptor channel. ${ }^{21}$ One hypothesis as to how $\mathbf{7}$ works is by normalising the increased activity of NMDA-receptors that has been reported in a number of neurodegenerative diseases, including AD, without affecting receptor function in non-pathological conditions. ${ }^{22}$ The normal function of the NMDA-receptor allows $\mathrm{Ca}^{2+}$ influx for neurotransmission, however, in the disease situation, increased activity of the NMDA-receptor may cause prolonged channel opening which leads to excessive $\mathrm{Ca}^{2+}$ influx, excitotoxicity and cell-death. ${ }^{23}$ Whether inhibiting excitotoxicity through NMDA receptors fully explains the efficacy of $\mathbf{7}$ in AD is unclear.

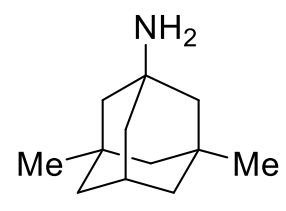

memantine (7)

Clinical trials of memantine for use in moderate to severe AD have shown positive effects on patient cognition and function, as well as associated societal benefits. ${ }^{24} \mathrm{~A}$ beneficial effect on patient quality of 
life, however, is inconclusive. ${ }^{25}$ Since many patients take both memantine and donepezil, a combination therapy, Namazaric, is now available as a convenient once-daily capsule. ${ }^{26}$

\section{Recent Clinical Failures}

Alzheimer's disease drug development has historically shown a remarkably high failure rate. In the decade of 2002-2012, 244 drugs were tested in AD clinical trials registered with clinicaltrials.gov. ${ }^{27}$ Only one of these, memantine (7), successfully completed clinical trials and was approved by the FDA; this represents a success rate of just $0.4 \%$. Highlighting this issue again are several recent, high-profile phase III clinical trial failures which have explored both the $\beta$-amyloid hypothesis (BACE1 inhibitors, anti-A $\beta$ antibodies) and other approaches (RAGE, PPAR, 5-HT6).<smiles>CN1C(N)=N[C@](C)(c2cc(NC(=O)c3ccc(F)cn3)ccc2F)CS1(=O)=O</smiles>

verubecestat (8)<smiles>CC#Cc1cncc(-c2ccc3c(c2)[C@]2(CC[C@@H](OC)CC2)N=C(C)C(N)=N3)c1</smiles>

lanabecestat (9)<smiles>CC(C)(C)OC(=O)c1ccc(NC(=O)c2ccc(C#N)cn2)cc1</smiles>

$\beta$-site amyloid precursor protein-cleaving enzyme 1 (BACE1, also known as $\beta$-secretase) is one of the enzymes responsible for the processing of APP to $A \beta$, and as such plays a key role in the $A \beta$ hypothesis of AD. Three different BACE inhibitors, verubecestat (8, Merck), lanabecestat (9, AstraZeneca \& Eli Lilly) and atabecestat $(\mathbf{1 0}$, Janssen) have recently failed in clinical trials. Verubecestat has been shown to reduce plasma, CSF and brain concentrations of toxic $A \beta$ species not only in animal models but also $A D$ patients. ${ }^{28}$ However, the EPOCH trial, testing the efficacy of verubecestat in mild to moderate AD patients, failed a futility analysis in early 2017. A second trial (APECS), testing verubecestat in prodromal AD was also halted early due to lack of efficacy. Results of the EPOCH trial have been recently published, and while CSF levels of $A \beta$ and brain amyloid load were shown to be decreased by drug treatment, this ultimately had no effect on slowing the progression of $A D$ in patients. ${ }^{29}$ Lanabecestat was under evaluation in two clinical trials AMARANTH (early AD) and DAYBREAK-ALZ (mild AD). In mid-2018, after failing interim futility analyses, both of these trials were halted. Results from these trials are yet to be published. Atabecestat 
had also been shown to be effective at reducing CSF concentrations of $A \beta_{1-40}{ }^{30}$ and so a phase II trial and a phase III trial were commenced in 2015. The phase II trial was aimed at studying the long-time safety and tolerability of atabecestat treatment, while the goal of the phase III trial (EARLY) was to study the effect of atabecestat treatment on cognitive decline in asymptomatic patients who were at risk of developing AD. Both of these trials were terminated early, due to observed elevations in patient liver enzymes, indicating liver toxicity. Taken together, these trials seem to indicate that targeting BACE1 to improve cognitive function in $A D$, at least for prodromal, mild and moderate $A D$ patients, would not appear to be a successful strategy so far.

Solanezumab (Eli Lilly) is a humanised monoclonal antibody which recognises the mid-domain of $A \beta$ and is selective for soluble $A B{ }^{31}$ Phase II studies had indicated that treatment with the antibody increased total levels of $A \beta$ in plasma, as well as increased levels of unbound $A \beta_{1-42}$ in CSF. ${ }^{32}$ EXPEDITION 1 and EXPEDITION 2 were two phase III studies initiated with mild to moderate AD patients. The primary outcomes were the change in scores on the Alzheimer's Disease Assessment Scale (ADAS) scale from baseline. $^{33}$ EXPEDITION 1 ended before EXPEDITION 2, and after the trial data had been analysed, a benefit was observed in patients with mild, but not moderate, AD. Therefore, the primary analysis population for EXPEDITION 2 was altered to patients with mild AD, but even with this change in primary outcome, the EXPEDITION 2 trial did not show any improvement in score. ${ }^{33} \mathrm{~A}$ third phase III clinical trial, EXPEDITION 3, was designed to further test the observation that solanezumab treatment showed a beneficial effect in patients with mild AD. ${ }^{34}$ Despite enrolling greater patient numbers than the previous two EXPEDITION trials, in late 2016 it was reported that EXPEDITION 3 had failed to meet its primary endpoint, with results published in early 2018 showing solanezumab treatment having no positive effect on cognitive decline. ${ }^{34}$

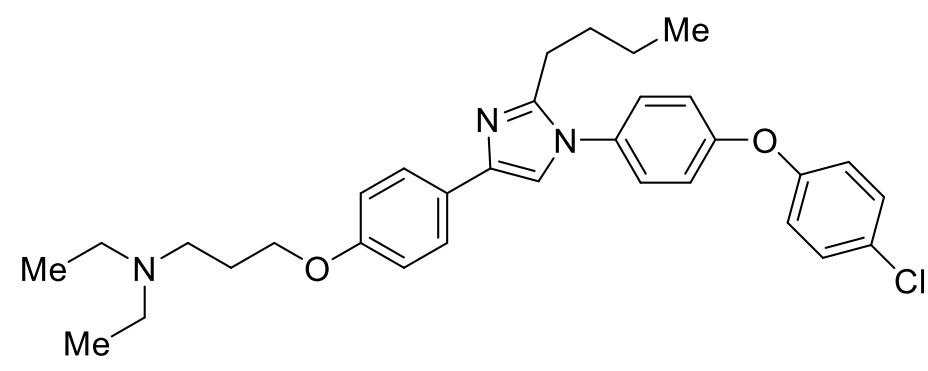

azeliragon (11)

Azeliragon (11, TTP488, vTv Therapeutics) is a small molecule inhibitor of The Receptor for Advanced Glycation Endproducts (RAGE). RAGE is a transmembrane receptor of the immunoglobulin superfamily, widely expressed by microglia and endothelial cells and known to be upregulated in $A D$. $A \beta$ is a known 
ligand for RAGE, and it is thought that RAGE promotes $A \beta$ influx into the brain, disrupting blood-brainbarrier (BBB) integrity. ${ }^{35}$ A phase II study of $\mathbf{1 1}$ showed that treatment for patients with mild AD gave statistically significant improvement in cognition over 18 months. ${ }^{36}$ A phase III study, STEADFAST, was then initiated, however this was terminated in mid-2018 due to lack of efficacy. The results have not yet been published.

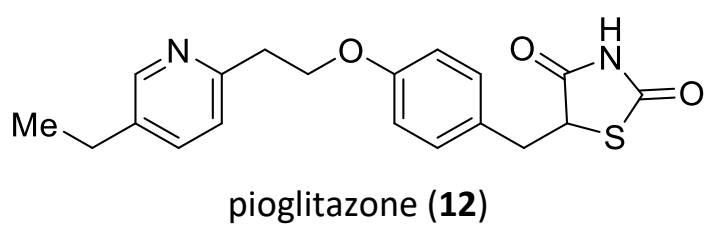

Pioglitazone (12) is an agonist of the nuclear receptor Peroxisome Proliferator-Activated Receptor $\gamma$ (PPAR- $\gamma$ ) which is an approved drug for the control of blood sugar in adults with type 2 diabetes. ${ }^{37}$ It has been shown that increases in tau phosphorylation and $A \beta$ deposition are promoted by increased insulin resistance, ${ }^{38}$ and that PPAR- $\gamma$ agonists are able to reduce both inflammation and amyloid plaque burden. ${ }^{39}$ In a small study of patients with mild $A D$, pioglitazone treatment was shown to improve cognition and regional cerebral blood flow. ${ }^{40}$ In 2013, Takeda and Zinfandel Pharmaceuticals began the TOMMORROW phase III trial with two main goals: to determine the effectiveness of pioglitazone in delaying onset of Mild Cognitive Impairment due to Alzheimer's disease (MCl-AD) and the second was to evaluate a new genetic test to identify individuals at risk of developing MCl-AD.$^{41}$ In early 2018 it was announced that the trial had failed an interim futility analysis and would be terminated, with results not yet published.<smiles>Fc1ccc2c(CCNCc3cccc(OCC(F)(F)C(F)F)c3)c[nH]c2c1</smiles>

idalopirdine (13)<smiles>O=S(=O)(c1ccccc1)c1cnc2c(N3CCNCC3)cccc2c1</smiles>

intepirdine (14)

Idalopirdine (13, Lundbeck \& Otsuka) is a small molecule serotonin 5-hydroxytryptamine-6 (5-HT6) antagonist. Antagonism of $5-\mathrm{HT}_{6}$ receptors has positive effects on cognitive function in animals, ${ }^{42}$ potentially through neurotransmitter modulation. ${ }^{43}$ Previous phase II trials of idalopirdine had not indicated a statistically significant effect on cognition, ${ }^{44}$ though a trial of idalopirdine in combination with donepezil showed a significant improvement in cognitive function compared to donepezil treatment alone. ${ }^{45}$ Three phase III studies (STARSHINE, STARBEAM, STARBRIGHT) were then conducted to establish 
efficacy of idalopirdine as an adjunctive therapy to acetylcholinesterase inhibitors for symptomatic treatment of patients with mild-moderate AD. ${ }^{46}$ For all 3 trials, 6 months of a combination of idalopirdine with 4, 5 or 6 did not improve cognition. ${ }^{46}$ The potential for $5-\mathrm{HT}_{6}$ antagonism as a viable AD therapy appears to be limited, especially in light of the previous failure of $5-\mathrm{HT}_{6}$ antagonist intepirdine (14) in a similar combination therapy approach (MINDSET). ${ }^{47}$

The multitude of clinical trial failures begs the question of whether the mechanisms were adequately tested. The answer is probably "yes and no" depending on the trail. Recently, Karran and Hardy presented a critique of the drug discovery and phase 3 clinical programs targeting the amyloid hypothesis for $A D$ which addresses this and other key questions. ${ }^{48}$ Solanezumab for example, had been observed to have the desired pharmacological effect (significant increase in unbound CSF $A \beta_{1-42}$ ) in AD patients, ${ }^{32}$ yet this did not correspond to improved cognition when compared to placebo treatment, even when tested in patients with mild $A D .{ }^{34}$ Verubecestat treatment had shown reductions in $A \beta_{40}, A \beta_{42}$ and $A P P \beta$ (the direct product of BACE activity) in AD patients..$^{28}$ Once again, this did not correspond to improved cognition compared to placebo, ${ }^{29}$ even when tested in patients with prodromal AD. Therefore, the failure of these particular trials does not appear to be a failure of drug-target engagement. For the amyloid hypothesis, it has been suggested that for therapeutic intervention to be effective, the agent may need to be applied prophylactically many years before amyloid deposition and cognitive decline are evident. ${ }^{49}$

At the beginning of 2018, there were 14 phase III trials addressing amyloid targets, with a movement towards treating cognitively normal patients with evidence of amyloid pathology. ${ }^{50}$ With more trials focussed on early-stage $A D$, however, a concern is that this will lead to a reduction in the number of trials being conducted for moderate to advanced $A D$ therapies. ${ }^{50} \mathrm{~A}$ more diverse range of targets implicated in different stages of $A D$ would therefore be of significant benefit to the $A D$ drug discovery pipeline.

\section{AD Treatments in Clinical trials}

In recent years, Cummings and co-workers have reported an annual comprehensive analysis of the AD drug development pipeline (Figure 4), ${ }^{50}$ along with recommendations for finding an effective way to treat or prevent AD by $2025 .{ }^{51}$ According to this analysis, as of January 2018, there are approximately 112 agents being investigated as potential treatments for $A D$ across 135 clinical trials. Other bodies such as Us Against Alzheimer's $\mathrm{s}^{52}$ and Alzheimer's Drug Discovery Foundation ${ }^{53}$ report broadly similar assessments. This section will give an overview encompassing representative drug candidates in phase $1 /$ II/III clinical trials across the three major $A D$ therapeutic treatment areas of symptomatic treatments, disease modifying therapies and neuroprotective/regenerative modalities. 


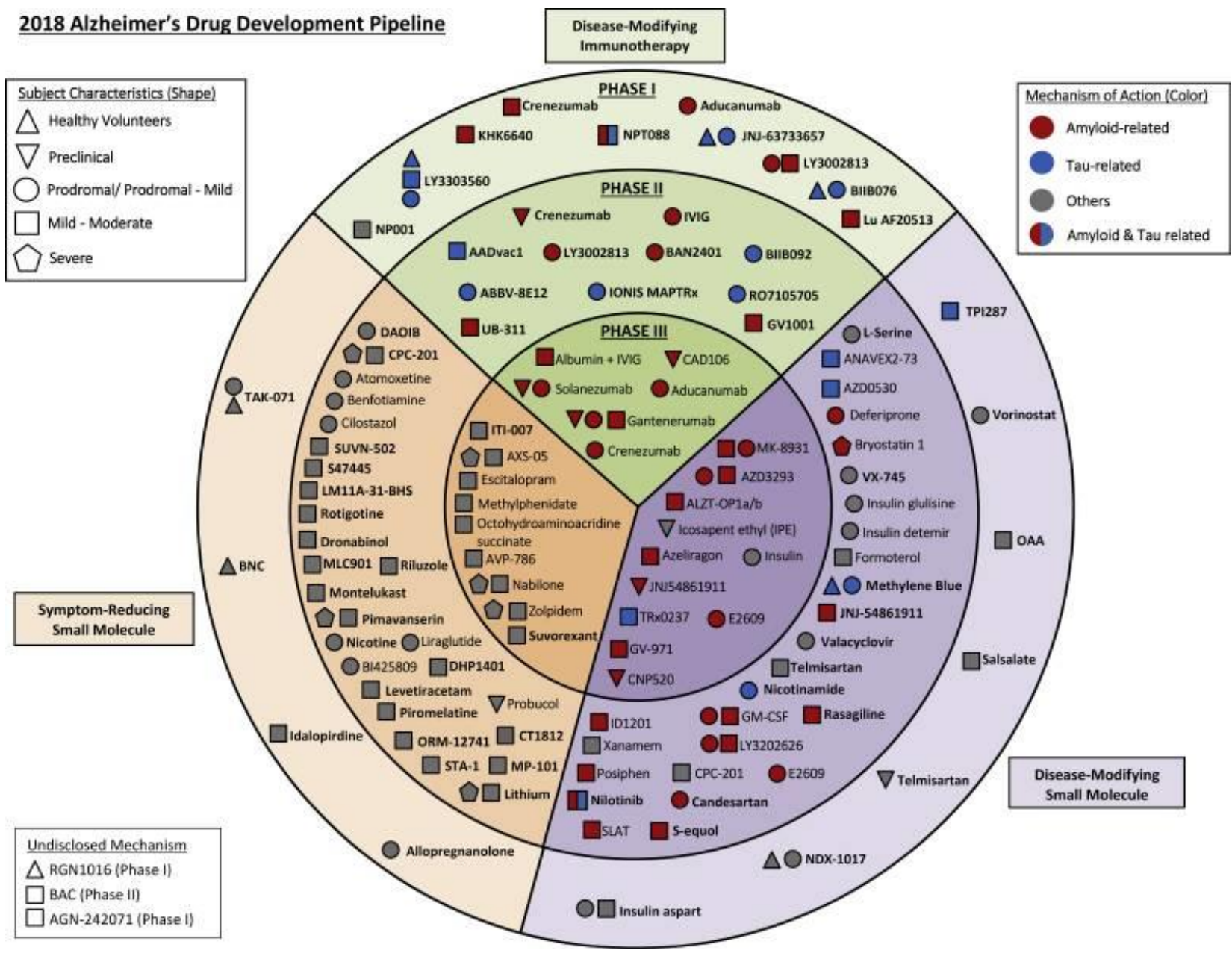

Figure 4: Agents in clinical trials for the treatment of Alzheimer's disease in 2018. From clinicaltrials.gov accessed $30^{\text {th }}$ January 2018. Reproduced from reference 50 with permission from J. Cummings (Cleveland Clinic Lou Ruvo Center for Brain Health). Copyright J. Cummings.

\section{Symptomatic}

Symptomatic agents attempt to alleviate the burden suffered by patients with $A D$, such as agitation and aggression, hallucinations and delusions, and insomnia. Of the current pipeline, approximately half of the agents in phase III trials are symptomatic, many of which are re-purposed from other indications without strong rationale as measured by a lack of peer-review studies and unreported clinical trial data. A selection of small molecule, symptomatic agents in clinical trials are discussed below.

A 2018 study into the factors associated with dementia-related behavioural crises found agitation and aggression to be the most commonly reported behavioural crisis, diminishing the quality of life of both people with dementia as well as their caregivers. ${ }^{54}$ Brexpiprazole (15, Otsuka \& Lundbeck) is a dopamine receptor D2 partial agonist approved to treat schizophrenia and as an adjunctive treatment for major 
depressive disorder. It is currently in phase III clinical trials for the treatment of agitation in patients with moderate to severe AD. Top-line results from these studies released in 2017 suggested an improvement in symptoms of agitation relative to placebo, however, full trial results are yet to be published. ${ }^{55}$ Tetrahydrocannabinol (THC) is known to have anxiolytic effects, and the CB1/CB2 partial agonist generic drug dronabinol (16, Johns Hopkins University) is currently in Phase II trials as an adjunctive therapy for treatment of severe agitation in $A D$ patients. ${ }^{56}$ Likewise, nabilone (17, Sunnybrook Health Sciences Centre) is a generic semisynthetic cannabinoid derivative registered in an ongoing small-scale phase III clinical trial looking for improvements in agitation in $A D$ patients. Positive preliminary results were presented at the annual Alzheimer's Association International Conference (AAIC, June 2018) and, on this basis, the sponsors have called for a larger trial to be initiated. ${ }^{57}$<smiles>O=c1ccc2ccc(OCCCCN3CCN(c4cccc5sccc45)CC3)cc2[nH]1</smiles>

brexpiprazole (15)<smiles>CCCCCCC(C)(C)c1cc(O)c2c(c1)OC(C)(C)[C@@H]1CCC(=O)C[C@H]21</smiles>

( \pm )-nabilone (17)<smiles>CCCCCc1cc(O)c2c(c1)OC(C)(C)C1(C)CCC(C)=CC21</smiles>

(-)-dronabinol (16)<smiles>CC(C)COc1ccc(CNC(=O)N(Cc2ccc(F)cc2)C2CCN(C)CC2)cc1</smiles>

pimavanserin (18)

Beyond treatments for agitation and aggression, pimavanserin (18, Acadia) is currently undergoing phase II/III clinical trials for treatment of psychotic symptoms, such as hallucinations and delusions in AD. Pimavanserin is a selective $5-\mathrm{HT}_{2 \mathrm{~A}}$ serotonin inverse agonist and was the first FDA approved treatment for Parkinson's disease psychosis. ${ }^{58}$ Suvorexant $(\mathbf{1 9}$, Merck) and lemborexant (20, Eisai) are novel nonbenzodiazepine treatments for insomnia that act as dual antagonists of the orexin receptors and are currently in phase III and II trials respectively. Dysregulation of the orexinergic system has recently been associated with irregular sleep-wake rhythm disorder in patients with moderate to severe AD. ${ }^{59}$ 


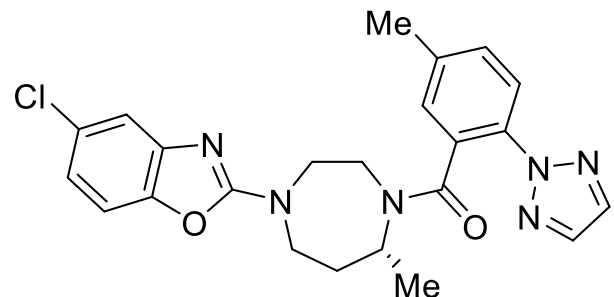

suvorexant (19)

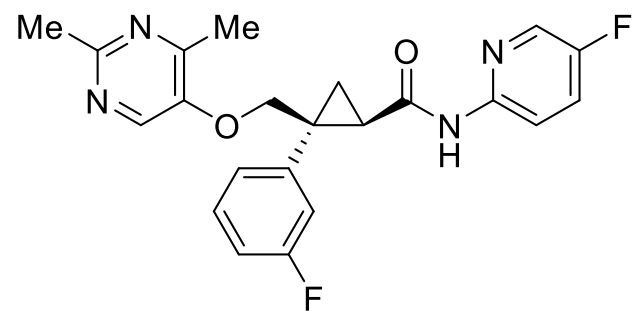

lemborexant (20)

\section{Disease Modifying}

More than $60 \%$ of the drugs currently in clinical trials can be described as 'disease modifying'; that is, treatments that attempt to alter the pathology of $A D$ with the aim of slowing down, stopping or even reversing the progression of the disease. Of those in phase III clinical trials, many are targeted at misfolded proteins, with most classed as anti-amyloid (11 agents) and one as anti-tau. Despite recent clinical failures, ${ }^{60}$ two of these are BACE inhibitors: elenbecestat (21, Eisai \& Biogen) and CNP520 (22, Novartis \& Amgen). ${ }^{61}$ CNP520 has been reported to show an improved selectivity profile for BACE1 over BACE2 and other aspartic proteases, which it is hoped will reduce off-target side-effects observed in patients with earlier generation BACE inhibitors. ${ }^{62}$ In healthy adults $>60$ years old, treatment with CNP520 was safe, well tolerated and resulted in robust, dose-dependent $A \beta$ reduction in CSF. Thus, long term studies with CNP520 have been initiated in the prevention of AD. ${ }^{62}$<smiles>C[C@H]1OC[C@]2(c3cc(NC(=O)c4cnc(C(F)F)cn4)ccc3F)N=C(N)SC[C@H]12</smiles>

elenbecestat (21)<smiles>[Y14][C@]1(c2nc(NC(=O)c3ncc(C(F)(F)F)cc3Cl)ccc2F)CO[C@](C)(C(F)(F)F)C(N)=N1</smiles>

CNP520 (22)

Immunotherapy represents another major misfolded protein strategy being pursued in the clinic with several passive anti-amyloid agents in phase II and III (Table 1) ${ }^{63}$ There is also the emergence of tau as a major target of interest with four passive anti-tau therapies in phase II. ${ }^{64}$ Additionally, there are a number of active immunity agents (vaccines) currently in phase II as both anti-amyloid ${ }^{65}$ and anti-tau therapies. ${ }^{66}$ 


\begin{tabular}{|c|c|c|c|}
\hline Agent & Clinical Status & Company & Notes \\
\hline \multicolumn{4}{|l|}{ Passive anti-A $\beta$ : } \\
\hline Aducanumab (BIIB037) & Phase III & Biogen & IgG1 monoclonal antibody \\
\hline albumin+immunoglobulin & Phase III & Instituto Grifols, S.A & - \\
\hline crenezumab & Phase III & Genentech \& Roche & IgG4 monoclonal antibody \\
\hline gantenerumab & Phase III & Chugai \& Roche & IgG1 monclonal antibody \\
\hline BAN2401 & Phase II & Biogen \& Eisai & $\begin{array}{l}\text { Humanized lgG1 monoclonal } \\
\text { antibody of mouse mAb158 }\end{array}$ \\
\hline LY3002813 & Phase II & Eli Lilly & $\begin{array}{l}\text { Humanized IgG1 monoclonal } \\
\text { antibody of mouse mE8-IgG2a }\end{array}$ \\
\hline KHK6640 & Phase I & Kyowa Hakko Kirin Co. & Anti-A $\beta$ peptide antibody \\
\hline \multicolumn{4}{|l|}{ Passive anti-tau: } \\
\hline ABBV-8E12 & Phase II & AbbVie & Humanized IgG4 antibody \\
\hline BIIB092 & Phase II & Biogen \& Bristol-Myers Squibb & Humanized IgG4 antibody \\
\hline LY3303560 & Phase II & Eli Lilly & Humanized tau antibody \\
\hline R07105705 & Phase II & Genentech \& Roche & Humanized IgG4 antibody \\
\hline BIIB076 & Phase I & Biogen \& Neurimmune & IgG1 monoclonal antibody \\
\hline JNJ-63733657 & Phase I & Janssen & Monoclonal antibody \\
\hline LY3303560 & Phase I & Eli Lilly & $\begin{array}{l}\text { Humanized monoclonal antibody } \\
\text { of mouse } \mathrm{MCl}-1\end{array}$ \\
\hline \multicolumn{4}{|l|}{ Active anti- $A \beta$ : } \\
\hline UB311 & Phase II & United Neuroscience & Synthetic peptide vaccine \\
\hline CAD106 & Phase II & Novartis & Synthetic peptide vaccine \\
\hline Lu AF20513 & Phase I & Lundbeck & Synthetic peptide vaccine \\
\hline \multicolumn{4}{|l|}{ Active anti-tau: } \\
\hline AADvac1 & Phase II & Axon Neuroscience & Synthetic peptide vaccine \\
\hline
\end{tabular}

Table 1: Immunotherapy and active immunity agents in clinical trials.

Beyond immunotherapy, a range of alternative mechanisms are being investigated to target the misfolded protein pathology observed in AD. Representative examples of intervention include: modulation of tau aggregation with TRx0237 (23, TauRx Therapeutics, Phase III), ${ }^{67}$ an agent which is somewhat controversial in the $A D$ community and failed to show signs of achieving its primary endpoint; ${ }^{68}$ reducing tau protein expression through antisense oligonucleotides (IONIS MAPTRx, Phase II); ${ }^{69}$ and inhibition of APP/tau mRNA translation by posiphen (24, QR Pharma, Phase II). ${ }^{70}$ 
<smiles>CN(C)c1ccc2c(c1)Sc1cc(N(C)C)ccc1N2</smiles>

TRx0237 (23)<smiles>CN1CC[C@]2(C)c3cc(OC(=O)Nc4ccccc4)ccc3N(C)[C@H]12</smiles>

posiphen (24)

There are also clinical approaches beyond directly targeting misfolded proteins such as restoring glucose homeostasis in the brain. ${ }^{71} \mathrm{~A}$ number of trials are exploring the use of treatments for type II diabetes to increase insulin signalling in the brain of $A D$ patients including: insulin, formulations of insulin for nasal delivery, and peptide liraglutide which is a long-acting derivative of incretin GLP-1. Recently, it has been proposed that AD may have a viral link ${ }^{72}$ and the anti-viral drug valaciclovir (25, Umeå University, phase II), used to treat herpes (HSV-1) infections, is currently recruiting patients with mild AD.<smiles>CC(C)[C@H](N)C(=O)OCCOCn1cnc2c(=O)[nH]c(N)nc21</smiles>

valaciclovir (25)

\section{Neuroprotective and Regenerative}

Treatments targeted at neuroprotection and cognitive enhancement are currently the most diverse in terms of mechanism of action and make up a larger proportion of therapies in early phase clinical trials. These include agents aimed at improving synapse plasticity and cognition such as AZD0530 (26, Yale University with drug supplied through AstraZeneca's Open Innovation Initiative) which is a repurposed dual Src and Abl kinase inhibitor acting through Fyn kinase inhibition, ${ }^{73}$ and BI425809 (no structure disclosed, Boehringer Ingelheim) a glycine transporter inhibitor. ${ }^{74}$ Modalities have been developed to prevent neuron loss and neurite dystrophy such as LM11A-31 (27, PharmatrophiX Inc.) which is targeted at the p75 neurotrophin receptor, ${ }^{75}$ and also reducing hippocampal hyperactivation through modulation of the synaptic vesicle protein $2 \mathrm{~A}$ (SV2A) with levetiracetam (28, AgeneBio). ${ }^{76}$<smiles>CN1CCN(CCOc2cc(OC3CCOCC3)c3c(Nc4c(Cl)ccc5c4OCO5)ncnc3c2)CC1</smiles>

AZD0530 (26)<smiles>[M]C(CC)C(N)C(=O)NCCN1CCOCC1</smiles>

LM11A-31 (27) 


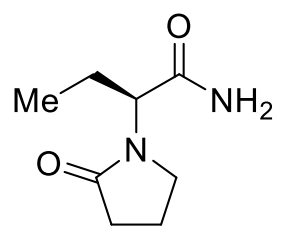

levetiracetam (28)

Therapies directed at neuronal regeneration are relative newcomers to the $A D$ pipeline and currently focussed around the use of human mesenchymal stem cells (hMSC) derived from adipose tissue, placental tissue or bone marrow. ${ }^{77}$ hMSC treatments being investigated for AD in phase I and II clinical trials include: Longeveron MSCs; CB-AC-02; Astrostem; and Neurostem. A small molecule approach to neuronal regeneration therapy, currently in phase I, is NDX-1017 (no structure disclosed, M3 Biotech.) which is targeted at activating the neurotrophic pathway through hepatocyte growth factor (HGF).

\section{Emerging preclinical approaches and the importance of neuroinflammation}

Approaches to develop disease modifying treatments for $A D$ ( $A \beta$ lowering and tau lowering) have until recently been largely driven by the human brain pathology of the disease, our understanding of disease biology from preclinical models, and the autosomal dominant mutations in APP, PSEN1, and PSEN2. However, a plethora of GWAS over recent years have identified >30 "risk genes" where a polymorphism in the gene has the effect of changing the risk of an individual to get AD. ${ }^{5}$ The strongest risk gene is Apoe4, however, despite 25 years of effort to understand its role in AD, ApoE4 remains somewhat enigmatic, and there has not been any significant efforts directed at Apoe4 as a drug target.

Beyond ApoE4, the risk genes identified can be categorized based upon their known biology and their cellular expression. The category with the largest number of these risk genes is "neuroinflammation", with expression, where known, localised to microglial cells. ${ }^{78}$ Microglia are the innate immune cells endogenous to the central nervous system (CNS). ${ }^{79}$ They share some aspects of their biology, and certainly aspects of their gene expression profile, with monocytes and macrophages and are the first line of immune defence for the CNS. Microglia also play a key role in constantly surveying their environment and scavenge misfolded protein or plaques, along with damaged or dying cells or synapses. The burgeoning weight of evidence is consistent with microglia playing an important role in AD. However, what remains unclear is whether microglia are functioning to exacerbate the disease, to mitigate against the disease, or both depending upon the stage of the disease. Thus, while modulation of microglia undoubtedly represents a credible approach to therapeutics for AD, exactly what "modulation" means is still to be defined. 
With this in mind, the risk gene TREM2, which can triple the likelihood of getting AD, has been a focus of activity. ${ }^{80}$ TREM2 is a cell surface expressed protein that can be activated by anionic ligands in the environment, leading to activation in intracellular signalling pathways, and subsequent effects of microglial function. TREM2 is the most intensely studied of the microglia risk genes with the belief that understanding its role will open up new targets for therapeutic intervention. A number of complementary approaches to modulate microglial function are being explored with the first examples now entering early clinical development. Denali Therapeutics have a TREM2-targeted antibody in early stage drug discovery and efforts are underway to take small molecules that modulate microglia function into drug development as well. Denali have progressed a RIPK1 kinase inhibitor DNL747 (no structure disclosed) into early stage development with the goal of normalising microglia inflammatory activity. ${ }^{81}$ Additional examples under investigation include the P2Y6 GPCR agonist GC021109 (no structure disclosed, Gliacure) in phase I supported by its anti-inflammatory activity at microglia ${ }^{82}$ and CSF1R inhibitors based upon their ability to inhibit microglia proliferation.$^{83}$ However, even though there is good basic science, microglia biology is still at an early phase with few quality tools to assess microglia in vitro and in vivo. ${ }^{81}$

\section{Conclusions and Future Direction}

Without doubt, there is clearly a need for superior drug therapies to treat $A D$ patients. There is significant value in the discovery of new symptomatic treatments for $A D$ patients as these symptoms are debilitating for the patients and have significant impact on their carers. This also represents an area of significant unmet medical need in the area of mental health and so these objectives are quite complementary. Therapies that target $A \beta$ have been the focus of efforts to develop a disease modification treatment for AD. BACE1 inhibitors and anti-A $\beta$ antibodies are the most advanced of these potential therapies, however, both approaches have failed to show clinical benefit so far. One widely held hypothesis to explain this failure is that the intervention occurred too late during the course of the disease ${ }^{84}$ Beyond the $\beta$-amyloid hypothesis, there are a number of newer approaches to treat $A D$ with neuroinflammation emerging as a very active area of research based on risk gene analysis. There is significant activity to interrogate and integrate GWAS risk gene data to understand cellular signalling pathways that may be perturbed in $A D$ and predict potential points for therapeutic intervention.

Along with improved drug therapies, it is also imperative that lessons are learned from AD clinical trials with negative outcomes to improve future study design. ${ }^{85}$ These improvements in trial design and interpretation will clearly benefit from an increased publication of trial data which is currently just $27 \%$ of completed trials. ${ }^{86}$ 
It is projected that by 2050 there will be 150 million people suffering with dementia globally with the majority having $A D .^{2}$ Effective treatments are urgently required to alleviate the symptoms and arrest progression of the disease. Despite a number of pharma companies exiting discovery-stage neuroscience research in recent years for commercial reasons, there is still a healthy AD research community dedicated to bring forward effective treatments that bring patient benefit. 


\section{Author Information}

*Corresponding Author:

PVF: Phone +44 (0)20 7679 6971; e.mail p.fish@ucl.ac.uk and paul.fish@crick.ac.uk.

ORCID:

Elliott D. Bayle:

0000-0002-7089-3858

Paul V. Fish:

0000-0002-2117-2173

David Steadman:

0000-0003-4271-5525

Paul Whiting:

0000-0002-4121-1379

Notes:

The manuscript was written through contributions of all authors. All authors have given approval to the final version of the manuscript.

\section{Acknowledgments}

This work was supported by the Alzheimer's Research UK (ARUK), the Francis Crick Institute, and the Dementia Research Institute. The ARUK UCL Drug Discovery Institute is core funded by Alzheimer's Research UK (registered charity No. 1077089 and SC042474). The Dementia Research Institute is core funded by the UK Medical Research Council, Alzheimer's Research UK, and the Alzheimer's Society. The Francis Crick Institute receives its core funding from Cancer Research UK (FC001002), the UK Medical Research Council (FC001002), and the Wellcome Trust (FC001002). We are grateful to Dr Tammaryn Lashley for the photographic images in Fig. 1, Professor Nick Fox for the MRI scans in Fig. 2, and Professor Jeffery Cummings for his permission to reproduce Fig. 4.

\section{Abbreviations}

$A \beta, \beta$-amyloid peptides; $A \beta_{1-40,} \beta$-amyloid peptide residues 1-40; $A D$, Alzheimer's disease; ApoE4, Apolipoprotein E4; APP, amyloid precursor protein; BACE1, $\beta$-site amyloid precursor protein-cleaving enzyme 1; BBB, blood-brain-barrier; $\mathrm{CB} 1$, cannabinoid receptor 1 ; ChE, cholinesterase; CNS, central nervous system; CSF, cerebrospinal fluid; CSF1R, colony stimulating factor 1 receptor; FAD, familial Alzheimer's disease; Fyn, proto-oncogene tyrosine-protein kinase Fyn; GLP-1, glucagon-like peptide-1; GWAS, genome wide association studies; hMSC, human mesenchymal stem cell; 5- $\mathrm{HT}_{6}$, 5hydroxytryptamine subtype-6; MRI, magnetic resonance imaging; NMDA-receptor, $N$-methyl-D-aspartate receptor; PET, positron emission tomography; PPAR- $\gamma$, peroxisome proliferator-activated receptor- $\gamma$; PSEN1, presenilin 1; P2Y6, P2Y purinoceptor 6; RAGE, receptor for advanced glycation endproducts; 
RIPK1, receptor-interacting serine/threonine-protein kinase 4; TREM2, triggering receptor expressed on myeloid cells 2 . 


\section{References and notes}

1. Alzheimer's Association. 2018 Alzheimer's disease facts and figures. Alzheimers Dement. 2018, 14, 367-429.

2. (a) Dementia fact sheet December 2017; World Health Organisation. http://www.who.int/newsroom/fact-sheets/detail/dementia. Accessed $1^{\text {st }}$ October 2018;

(b) https://www.alzheimersresearchuk.org/about-dementia/facts-stats/ Accessed $8^{\text {th }}$ August 2018.

3. (a) Lane, C. A., Hardy, J., Schott J. M. Alzheimer's disease. Eur. J. Neurol. 2018, 25, 59-70.

(b) Cipriani, G., Dolciotti, C., Picchi, L., Bonuccelli, U. Alzheimer and his disease: a brief history. Neurol. Sci. 2011, 32, 275-279.

4. (a) Hardy, J. A., Higgins, G. A. Alzheimer's disease: the amyloid cascade hypothesis. Science 1992, $256,184-185$.

(b) Selkoe, D. J., Hardy, J. The amyloid hypothesis of Alzheimer's disease at 25 years. EMBO Mol. Med. 2016, 8, 595-608.

5. Guerreiro, R., Hardy, J. Genetics of Alzheimer's disease. Neurotherapeutics. 2014, 11, 732-7.

6. Pangalos, M. N., Schechter, L. E., Hurko, O. Drug development for CNS disorders: strategies for balancing risk and reducing attrition. Nat. Rev. Drug Discov. 2007, 6, 521-532.

7. Webster, L. et al. Core outcome measures for interventions to prevent or slow the progress of dementia for people living with mild to moderate dementia: Systematic review and consensus recommendations. PLOS ONE, 2017, 12, e0179521.

8. Blennow $\mathrm{K}$ ' Zetterberg H. Biomarkers for Alzheimer disease - current status and prospects for the future. J. Intern. Med. 2018. doi: 10.1111/joim.12816, Epub ahead of print.

9. Villemagne, V. L, Doré, V., Burnham, S. C., Masters, C. L., Rowe, C. C. Imaging tau and amyloid- $\beta$ proteinopathies in Alzheimer disease and other conditions. Nat. Rev. Neurol. 2018, 14, 225-236.

10. Drachman, D. A., Leavitt, J. Human Memory and the Cholinergic System. Arch. Neurol. 1974, 30, 113-121.

11. Gray, S. L. et al. Cumulative Use of Strong Anticholinergics and Incident Dementia. JAMA Intern. Med. 2015, 175, 401-407.

12. Hampel, H. et al. The cholinergic system in the pathophysiology and treatment of Alzheimer's disease. Brain 2018, 141, 1917-1933.

13. Massoud, F., Gauthier, S. Update on the Pharmacological Treatment of Alzheimers Disease. Curr. Neuropharmacol. 2010, 8, 69-80.

14. Hansen, R. A. et al. Efficacy and safety of donepezil, galantamine, and rivastigmine for the treatment of Alzheimer's disease: a systematic review and meta-analysis. Clin. Interv. Aging 2008, $3,211-225$. 
15. Wattmo, C., Wallin, A. K., Londos, E., Minthon, L. Risk Factors for Nursing Home Placement in Alzheimer's Disease: A Longitudinal Study of Cognition, ADL, Service Utilization, and Cholinesterase Inhibitor Treatment. Gerontologist 2011, 51, 17-27.

16. Feldman, H. et al. Efficacy of donepezil on maintenance of activities of daily living in patients with moderate to severe Alzheimer's disease and the effect on caregiver burden. J. Am. Geriatr. Soc. 2003, 51, 737-744.

17. Adler, G., Mueller, B., Articus, K. The transdermal formulation of rivastigmine improves caregiver burden and treatment adherence of patients with Alzheimer's disease under daily practice conditions. Int. J. Clin. Pract. 2014, 68, 465-470.

18. Wallin, Å. K. et al. Donepezil in Alzheimer's Disease: What to Expect after 3 Years of Treatment in a Routine Clinical Setting. Dement. Geriatr. Cogn. Disord. 2007, 23, 150-160.

19. Petersen, R. C. et al. Vitamin E and Donepezil for the Treatment of Mild Cognitive Impairment. $N$. Engl. J. Med. 2005, 352, 2379-2388.

20. Lipton, S. A. Paradigm shift in neuroprotection by NMDA receptor blockade: Memantine and beyond. Nat. Rev. Drug Discov. 2006, 5, 160-170.

21. Chen, H. S. et al. Open-channel block of N-methyl-D-aspartate (NMDA) responses by memantine: therapeutic advantage against NMDA receptor-mediated neurotoxicity. J. Neurosci. 1992, 12, 4427-4436.

22. Epstein, F. H., Lipton, S. A., Rosenberg, Excitatory Amino Acids as a Final Common Pathway for Neurologic Disorders. N. Engl. J. Med. 1994, 330, 613-622.

23. Lipton, S. A., Nicotera, P. Calcium, free radicals and excitotoxins in neuronal apoptosis. Cell Calcium 1998, 23, 165-171.

24. Wilkinson, D. A review of the effects of memantine on clinical progression in Alzheimer's disease. Int. J. Geriatr. Psychiatry 2012, 27, 769-776.

25. Alam, S., Lingenfelter, K. S., Bender, A. M., Lindsley, C. W. Classics in Chemical Neuroscience: Memantine. ACS Chem. Neurosci. 2017, 8, 1823-1829.

26. Greig, S. L. Memantine ER/Donepezil: A Review in Alzheimer's Disease. CNS Drugs 2015, 29, 963970.

27. Cummings, J. et al Alzheimer's disease drug-development pipeline: few candidates, frequent failures. Alzheimer's Research \& Therapy 2014, 6, 37.

28. Kennedy, M. E. et al. The BACE1 inhibitor verubecestat (MK-8931) reduces CNS $\beta$-amyloid in animal models and in Alzheimer's disease patients. Sci. Transl. Med. 2016, 8, 363ra150.

29. Egan, M. F. et al. Randomized Trial of Verubecestat for Mild-to-Moderate Alzheimer's Disease. N. Engl. J. Med. 2018, 378, 1691-1703. 
30. Timmers, M. et al. Pharmacodynamics of atabecestat (JNJ-54861911), an oral BACE1 inhibitor in patients with early Alzheimer's disease: randomized, double-blind, placebo-controlled study. Alzheimers. Res. Ther. 2018, 10, 85-103.

31. DeMattos, R. B. et al. Peripheral anti-A antibody alters CNS and plasma A clearance and decreases brain A burden in a mouse model of Alzheimer's disease. Proc. Natl. Acad. Sci. 2001, 98, 8850-8855.

32. Farlow, M. et al. Safety and biomarker effects of solanezumab in patients with Alzheimer's disease. Alzheimer's Dement. 2012, 8, 261-271.

33. Doody, R. S. et al. Phase 3 Trials of Solanezumab for Mild-to-Moderate Alzheimer's Disease. N. Engl. J. Med. 2014, 370, 311-321.

34. Honig, L. S. et al. Trial of Solanezumab for Mild Dementia Due to Alzheimer's Disease. N. Engl. J. Med. 2018, 378, 321-330.

35. Kook, S.-Y. et al. A 1-42-RAGE Interaction Disrupts Tight Junctions of the Blood-Brain Barrier Via Ca2+-Calcineurin Signaling. J. Neurosci. 2012, 32, 8845-8854.

36. Burstein, A. H. et al. Effect of TTP488 in patients with mild to moderate Alzheimer's disease. BMC Neurol. 2014, 14, 12-20.

37. Yasmin, S., Jayaprakash, V. Thiazolidinediones and PPAR orchestra as antidiabetic agents: From past to present. Eur. J. Med. Chem. 2017, 126, 879-893.

38. Neumann, K. et al. Insulin Resistance and Alzheimers Disease: Molecular Links \&amp; Clinical Implications. Curr. Alzheimer Res. 2008, 5, 438-447.

39. Heneka, M. T. et al. Acute treatment with the PPARy agonist pioglitazone and ibuprofen reduces glial inflammation and Aß1-42 levels in APPV717I transgenic mice. Brain 2005, 128, 1442-1453.

40. Sato, T. et al. Efficacy of PPAR- $\gamma$ agonist pioglitazone in mild Alzheimer disease. Neurobiol. Aging 2011, 32, 1626-1633.

41. Crenshaw, D. G. et al. Using genetics to enable studies on the prevention of Alzheimer's disease. Clin. Pharmacol. Ther. 2013, 93, 177-185.

42. Meneses, A. Effects of the 5-HT(6) receptor antagonist Ro 04-6790 on learning consolidation. Behav. Brain Res. 2001, 118, 107-110.

43. Rodríguez, J. J., Noristani, H. N., Verkhratsky, A. The serotonergic system in ageing and Alzheimer's disease. Prog. Neurobiol. 2012, 99, 15-41.

44. Maher-Edwards, G. et al. Double-blind, controlled phase II study of a 5-HT6 receptor antagonist, SB-742457, in Alzheimer's disease. Curr. Alzheimer Res. 2010, 7, 374-385.

45. Wilkinson, D., Windfeld, K., Colding-Jørgensen, E. Safety and efficacy of idalopirdine, a 5-HT6 receptor antagonist, in patients with moderate Alzheimer's disease (LADDER): a randomised, double-blind, placebo-controlled phase 2 trial. Lancet Neurol. 2014, 13, 1092-1099. 
46. Atri, A. et al. Effect of Idalopirdine as Adjunct to Cholinesterase Inhibitors on Change in Cognition in Patients With Alzheimer Disease. JAMA 2018, 319, 130-142.

47. Khoury, R., Grysman, N., Gold, J., Patel, K., Grossberg, G. T. The role of 5HT6-receptor antagonists in Alzheimer's disease: an update. Expert Opin. Investig. Drugs 2018, 27, 523-533.

48. Karran, E., Hardy, J. A Critique of the Drug Discovery and Phase 3 Clinical Programs Targeting the Amyloid Hypothesis for Alzheimer Disease. Ann. Neurol. 2014, 76, 185-205.

49. Karran, E., De Strooper, B. The amyloid cascade hypothesis: are we poised for success or failure? J. Neurochem. 2016, 139, 237-252.

50. Cummings, J., Lee, G., Ritter, A., Zhong, K. Alzheimer's disease drug development pipeline: 2018. Alzheimer's Dement. Transl. Res. Clin. Interv. 2018, 4, 195-214.

51. Cummings, J., Aisen, P. S., DuBois, B. et al. Drug development in Alzheimer's disease: the path to 2025. Alzheimer's Res. Ther. 2016, 8, 39.

52. https://www.usagainstalzheimers.org/sites/default/files/2018. Alzheimer's drug pipeline - the current state of Alzheimers drug development (pdf). Accessed $27^{\text {th }}$ September 2018.

53. https://www.alzdiscovery.org/research-and-grants/clinical-trials-report. Accessed $27^{\text {th }}$ September 2018

54. Backhouse, T., Camino, J., Mioshi. E. What do we know about behavioral crises in dementia? A systematic review. J. Alzheimer's Dis. 2018, 62, 99-113.

55. https://clinicaltrials.gov/ct2/keydates/NCT01922258. Accessed $12^{\text {th }}$ November 2018.

56. Forester, B., Romano, C., Quayle, W., Georgakas, J., Rosenberg, P. B. Pilot trial of dronabinol adjunctive treatment of agitation in alzheimer's disease (AD) (THC-AD). Alzheimer's Dement. 2017, $13,940$.

57. https://www.alz.org/aaic/downloads2018/Tue-am-briefing-non-cognitive-dementiasymptoms.pdf. Accessed $12^{\text {th }}$ November 2018.

58. Kitten, A. K., Hallowell, S. A., Saklad, S. R., Evoy, K. E. Pimavanserin: a novel drug approved to treat Parkinson's disease psychosis. Innov. Clin. Neurosci. 2018, 15, 16-22.

59. Liguori, C., Romigi, A., Nuccetelli, M., et al. Orexinergic system dysregulation, sleep impairment, and cognitive decline in alzheimer disease. JAMA Neurology 2014, 71, 1498-1505.

60. Mullard, A. BACE failures lower AD expectations, again. Nat. Rev. Drug Disc. 2018, $17,385$.

61. (a) Yan, R. Stepping closer to treating Alzheimer's disease patients with BACE1 inhibitor drugs. Transl. Neurodegener. 2016, 5, 13; (b) Ghosh, A. K., Ca'rdenas, E. L., Osswald, H. L. The Design, 
Development, and Evaluation of BACE1 Inhibitors for the Treatment of Alzheimer's Disease. Top. Med. Chem. 2017, 24, 27-86.

62. Neumann, U., Ufer, M., Jacobson, L. H., et al. The BACE-1 inhibitor CNP520 for prevention trials in Alzheimer's disease. EMBO Mol. Med. 2018, e9316.

63. Mo, J. J., Li, J., Yang, Z., Liu, Z., Feng, J. S. Efficacy and safety of anti-amyloid- $\beta$ immunotherapy for Alzheimer's disease: a systematic review and network meta-analysis. Ann. Clin. Transl. Neur. 2017, 4, 931-942.

64. Funk, K.E., Mirbaha, H., Jiang, H., Holtzman, D. M., Diamond, M. I. Distinct Therapeutic Mechanisms of Tau Antibodies: Promoting microglial clearance versus blocking neuronal uptake. J. Biol. Chem. 2015, 290, 21652-21662.

65. Wang, C. Y., Finstad, C. L., Walfield, A. M., et al. Site-specific UBITh ${ }^{\circledR}$ amyloid- $\beta$ vaccine for immunotherapy of Alzheimer's disease. Vaccine 2007, 25, 3041-3052.

66. Kontsekova, E., Zilka, N., Kovacech, B., Novak, P., Novak, M. First-in-man tau vaccine targeting structural determinants essential for pathological tau-tau interaction reduces tau oligomerisation and neurofibrillary degeneration in an Alzheimer's disease model. Alzheimers Res. Ther. 2014, 6, 44.

67. Wischik, C. M., Edwards, P.C., Lai, R. Y., Roth, M., Harrington, C. R. Selective inhibition of Alzheimer disease-like tau aggregation by phenothiazines. Proc. Nat. Acad. Sci.. 1996, 93, 1121311218.

68. (a) Gauthier, S., Feldman, H. H., Schneider, L. S., et al. Efficacy and safety of tau-aggregation inhibitor therapy in patients with mild or moderate Alzheimer's disease: a randomised, controlled, double-blind, parallel-arm, phase 3 trial. Lancet 2016, 388, 2873-2884.

(b) In first phase 3 trial, the tau drug LMTM did not work. Period. ALZFORUM NEWS, $29^{\text {th }}$ July 2016. See: 'https://www.alzforum.org/news/conference-coverage/first-phase-3-trial-tau-drugImtm-did-not-work-period'. Accessed $5^{\text {th }}$ October 2018.

69. DeVos, S. L., Miller, R. L., Schoch, K. M., et al. Tau Reduction Prevents Neuronal Loss and Reverses Pathological Tau Deposition and Seeding in Mice with Tauopathy. Sci. Transl. Med. 2017, 9, eaag0481.

70. Teich, A. F., Sharma, E., Barnwell, E., et al. Translational inhibition of APP by Posiphen: Efficacy, pharmacodynamics, and pharmacokinetics in the APP/PS1 mouse. Alzheimers Dement. 2018, 4, 37-45.

71. Wijesekara, N., Gonçalves, R. A., De Felice, F. G., Fraser, P. E. Impaired peripheral glucose homeostasis and Alzheimer's disease. Neuropharmacology 2018, 136, 172-181. 
72. Readhead, B., Haure-Mirande, J.-V., Funk, C. C., et al. Multiscale Analysis of Independent Alzheimer's Cohorts Finds Disruption of Molecular, Genetic, and Clinical Networks by Human Herpesvirus. Neuron. 2018, 99, 64-82.

73. Kaufman, A. C., Salazar, S. V., Haas, L.T., et al. Fyn Inhibition Rescues Established Memory and Synapse Loss in Alzheimer Mice. Ann. Neurol. 2015, 77, 953-971.

74. Moschetti, V., Schlecker, C., Wind, S., et al. Multiple Rising Doses of Oral BI425809, a GlyT1 Inhibitor, in Young and Elderly Healthy Volunteers: A Randomised, Double-Blind, Phase I Study Investigating Safety and Pharmacokinetics. Clin. Drug Investig. 2018, 38, 737-750.

75. Simmons, D. A., Knowles, J.K., Belichenko, N.P., et al. A Small Molecule p75NTR Ligand, LM11A-31, Reverses Cholinergic Neurite Dystrophy in Alzheimer's Disease Mouse Models with Mid- to LateStage Disease Progression. PLoS ONE. 2014, 9, e102136.

76. Bakker, A., Albert, M. S., Krauss, G., Speck, C. L., Gallagher, M. Response of the medial temporal lobe network in amnestic mild cognitive impairment to therapeutic intervention assessed by fMRI and memory task performance. Neurolmage Clin. 2015, 7, 688-698.

77. Bali, P., Lahiri, D. K., Banik, A., Nehru, B., Anand, A. Potential for Stem Cells Therapy in Alzheimer's Disease: Do Neurotrophic Factors Play Critical Role? Current Alzheimer Res. 2017, 14, 208-220.

78. Villegas-Llerena, C., Phillips, A., Garcia-Reitboeck, P., Hardy, J., Pocock, J. M. Microglial genes regulating neuroinflammation in the progression of Alzheimer's disease. Curr. Opin. Neurobiol. 2016, 36, 74-81.

79. Colonna, M., Butovsky, O. Microglia Function in the Central Nervous System During Health and Neurodegeneration. Ann. Rev. Immunol. 2017, 35, 441-468.

80. Ulrich, J. D., Ulland, T. K, Colonna, M., Holtzman, D. M. Elucidating the Role of TREM2 in Alzheimer's Disease. Neuron. 2017, 94, 237-248.

81. Mullard A. Microglia-targeted candidates push the Alzheimer drug envelope. Nat. Rev. Drug. Discov. 2018, 17, 303-305.

82. $\quad$ https://www.alzforum.org/therapeutics/gc-021109). Accessed $8^{\text {th }}$ August 2018.

83. http://www.dementiaconsortium.org/brain-inflammation-targeted-in-first-drug-discoveryproject-from-3m-dementia-consortium/). Accessed $8^{\text {th }}$ August 2018.

84. Sperling, R., Mormino, E., Johnson, K. The evolution of preclinical Alzheimer's disease: implications for prevention trials. Neuron. 2014, 84, 608-622.

85. Cummings, J. Lessons Learned from Alzheimer Disease: Clinical Trials with Negative Outcomes. Clin. Transl. Sci. 2018, 11, 147-152. 
86. Yilmaz, T., Jutten, R. J., Santos, C. Y., Hernandez, K. A., Snyder. P. J. Discontinuation and nonpublication of interventional clinical trials conducted in patients with mild cognitive impairment and Alzheimer's disease. Alzheimers Dement. 2018, 4, 161-164. 